\title{
Stimulation of child's sexual imitation behavior through Neurolinguistic programming
}

\author{
Edhy Rustan \\ Institut Agama Islam Negeri Palopo, Indonesia
}

\begin{tabular}{l}
\hline Article Info \\
\hline Article history: \\
Received Nov 12th, 2019 \\
Revised Mar 31st, 2020 \\
Accepted Apr 29th, 2020
\end{tabular}

Keyword:

Child

Neurolinguistic programming

Sexual imitation

\begin{abstract}
This study aims to determine the forms of child sexual imitation behavior, influencing factors and the role of parents and teachers in addressing the sexual imitation of children. This type of research is descriptive qualitative research using direct observation and interview methods as research data sources. The results of this study indicate that children engage in sexual imitation in the form of sexual movements. This behavior is caused by errors in parenting. Parenting is too permissive so that it does not allow the child to sleep alone as a result the child sees his parents having sexual relations and imitates them when playing or studying at school. In dealing with these behaviors, a Neurolinguistic Programming (NLP) approach can be used where parents play a role in training the independence of children by (1) creating a pleasant atmosphere for children (2) giving positive suggestions through fairy tales. While in school teachers provide positive education and suggestions through learning programs in schools by integrating sexual education into the appropriate learning themes.
\end{abstract}

C 2020 The Authors. Published by Indonesian Institute for Counseling,

Education and Therapy (IICET). This is an open access article under the CC BY license (https://creativecommons.org/licenses/by/4.0/)

\author{
Corresponding Author: \\ Edhy Rustan; \\ Institut Agama Islam Negeri Palopo \\ Email: edhy_rustan@iainpalopo.ac.id
}

\section{Introduction}

The child's golden age depends on the age of 3-5 years. At this time children become more critical to imitate everything around them including the problem including the concentrated behavior that has sex (Mcguigan, Whiten, Flynn, \& Horner, 2007). According to Sigmund Freud (2001), in that age range children are in the Phallic stage with the characteristics of the development of a sexy child becoming very visible. The development of the section marked by tools that support the child becomes the center of attention. Reinforced by Hurlock (1996) which states, children's attitudes and sections in the phallic stage regulate by the development of curiosity which is greatly increased. This stage becomes a critical time for children when children look for more things about sex by exchanging ideas with friends, playing genitals with friends or attracting them to the opposite sex. The development of the child section needs the help of parents in educating and guiding children and an environment conducive to supporting child development (Hornor, 2004).

The development of sexuality is not only about sexual relations, but also addresses aspects of regulating values, attitudes, feelings, identity, interactions, and behavior. In the discussion of sex development, it does not mean that children only think about sex. The development of sexuality also develops transitional, social, cultural and physical aspects. What children discuss, consider and feel about sex will determine their sexual attitudes and behavior later (Miller, 2016; Wurtele, 1993). The development of child sexuality consists of 5 stages, namely: 1) Oral mouth becomes the most important part related to the fulfillment of food and drinking needs. The oral stages end before the child has not received direct nutritional intake from submitting. 2) anal phase where libido is distributed to the anal area or called anal erotic which occurs at the age of 2-3 years. When the rectum releases food pulp it will draw attention to the child and the bowel 
movement becomes a release that will be received and satisfaction or pleasure will be obtained. 3) The phallic stage where the child begins to pay attention or play with his genitals. At this time the development of children is needed by psychososiological families that required the role and commitment of parents to the child's development. 4) latent stages when the development of a child's section is restrained or depressed. Children develop sublimation skills more and the focus of children's attention turns to friendship. 5) The genital stage that occurs at the age of 12 or 13 years. At this time, organs replaced by children have appeared and appeared that others want to pay attention to.

Parents as the first source of information for children are important in the process of assistance and development to be able to walk into a role model and provide sex information following the child's development (Baumeister, Flores, \& Mann, 1995; Dryler, 2014). Besides, parents also collect information and filter information obtained by children both from the media and from the surrounding environment. Based on the results of interviews with several parents in the city of Palopo, it can be suggested that they are still less able to play their role as parents in the discussion and filter the information received by children about sexuality.

Parents let their children sleep in the same room with them, so sometimes the child unconsciously witnesses their parents having sex. Watching parents have sexual relations that can cause children to change Post Traumatic Stress Disorder (PTSD) which can change the child's mindset about sex (Green et al., 1989). PTSD is a problem experienced by someone who experiences a traumatic event and this individual is not able to eliminate the memory of events that have been experienced before (Gutermann et al., 2016). This disorder can occur for weeks, months to years and can also occur after a few months or years-the individual experiences an increase. PTSD sufferers will overcome conflicts, sleep difficulties, tension and other reactions (Boroughs et al., 2015). The provision of cognitive therapy can be a solution to PTSD and will provide optimal results if given earlier and involve parents (Gutermann et al., 2016).

Ratih Zulhaqi (2013) Child and adolescent psychologist, children can sleep separately with their parents in the age range of 2 to 5 years. Often the reason parents are reluctant to sleep apart from their children because parents feel freer to control their children, feel safe so they can sleep well and for busy parents can be a moment of gathering together with children.

Based on preliminary studies of early childhood sex deviations in Paramata Bunda Kindergarten, there is deviant student behavior. This is evident when students want to eat together as a closing activity. Before eating the children are directed to wash their hands first in turn. While waiting for their turn to wash their hands, a male student approached a female friend of his age then played together who then suddenly made a sexual move. In a study conducted by Mcquigan et al (2007) entitled "Imitation of Causally Opaque Versus Causally Transparent Tool Use By 3 and 5-Year-Old Children, "this study is related to how children aged 3 and 5 years in imitating actions taken by adults both in life or through video. His findings show that children aged 3-5 years are good imitators without thinking about the effects they cause, but after being given information about the actions of the children begin to exclude irrelevant actions. Furthermore, Miller's research (2016) entitled "Family Influences on Adolescent Sexual and Contraceptive Behavior Family Influences on Adolescent Sexual and Contraceptive Behavior" found that sexual behavior in adolescents is strongly influenced by families both from frequent exposure to sexual activity and education provided.

Prevention and early intervention in sexual imitation behavior by children. Therefore, they need to do Neurolinguistic Programming so that the neurological process in providing understanding can run smoothly. NLP discusses how nerves and languages can work together to change the way people think and behave (Tosey \& Mathison, 2010). NLP can be applied to children who experience social, emotional and behavioral difficulties. The method used can be visualization, positive suggestion, role models and relaxation (Squirell, 2008). NLP can be done by using certain word patterns in describing something so that mental processes occur that affect behavior in achieving goals (Rustan, 2017). The provision of information optimizes the potential of the child's brain through nerve stimulation by coordinating the role of memory associated with the human senses, specifically visual and imagination memory, and the sense of hearing and psychological condition of the child.

Based on this description, sex education using a neurolinguistic approach needs to be pursued under the stages of child development and the sexual life of their parents. Therefore, this study will examine the sexual lives of students' parents, the arrangement of the room at home, parenting and other matters related to the act of child sexual imitation. This research focuses on: (1) Forms of sexual imitation behavior of students in Paramata Bunda Kindergarten (2) Factors that cause sexual imitation behavior of Paramata Bunda 
Kindergarten students and, (3) Efforts made by parents and teachers to handle children who are behaving sexual imitation.

\section{Method}

This research is a qualitative descriptive study that aims to illustrate the facts regarding: (1) the form of sexual imitation behavior of TK Pramata Bunda students (2) the factors that cause the sexual imitation behavior of TK Pramata Bunda students (3) efforts made by parents and teachers to handle sexual imitation behavior of Pramata Bunda Kindergarten students. In this study, researchers used data from informants as primary data and were also supported by secondary data. The data search focused on the form, the causes and the efforts or roles of parents and teachers to overcome child sexual imitation behavior. This research was conducted on children who perform sexual imitation behavior. Direct observations and in-depth interviews with students, peers, parents, and teachers are used as a method of collecting research data. The data is then analyzed using the Miles and Huberman models.

\section{Results and Discussion}

\section{Forms of child sexual imitation behavior}

Based on observations obtained a form of child sexual imitation, in the form of imitations of movements that have been seen. Children often wiggle their backs slowly when standing or up and down if on his stomach. The child crushes a female friend when she is on her back, then turns her girlfriend's body over and over. Based on that, it can be said that children imitate sexual movements without realizing that the movements carried out smelled of sex. This was confirmed by the results of interviews with parents of children, who said that "after finding us in touch, my child often imitates me over my body when we are playing together at home". Likewise with the phrase the child "I saw mama and daddy fighting in bed", "I rolled around friends as my daddy did"

Based on observations and interviews, it can be illustrated that children perform sexual movements as seen at home. In this case, the sexual behavior of their parents. The majority of children who engage in sexual movements are children who share a room with their parents. The sexual movements carried out together with the sexual behavior of parents witnessed by children in his home. This is in line with what was stated by Hurlock (1999) namely the child's sexual attitudes and behavior are influenced by the rapid development of children's curiosity at the phallic stage. The existence of a great curiosity causes children to imitate all the behavior carried out by people around them both good and bad behavior so that this phase is referred to as a critical phase in child development. Mcguigan et al. (2007) reinforce the opinion that children aged 3-5 years are very capable of imitating movements that are exemplified visually both through video and in person.

\section{Factors affecting children's sexual imitation behavior}

Sexual imitation behavior is influenced by parenting factors. When parents see their child doing sexual movements, they only shout and ask that the child stop doing the action without any explanation of the behavior. The results of interviews obtained from the child's parents that "when the child plays his genitals I scolded him and told him to stop with the reason that is not good deeds without excessive explanation because it is still taboo for children", "I always avoid child questions that smell of sex because they feel it's not appropriate for them ". Also, some parents say "I have found children watch obscene videos on YouTube and make them wonder about the movements they are doing, but as a parent, I never give an explanation to children about sexuality because they feel it's not the time". One child also said that "I don't know why my mother is always angry when I hold my bird".

Besides, the factor of education in schools that do not accommodate sex education for children. The curriculum used is only limited to gender differences. The results of interviews with teachers revealed that "in the curriculum we use, children are only limited to gender differences", "my friend and I have not found the right method in teaching children about sex". Referring to the results of the interview, it can be stated that, the teacher does not yet have a learning design that facilitates sex learning for young children. Parents who are still sleeping together with children are also very contributing factors to the child's sexual imitation. Sometimes children accidentally witness their parents having sexual relations. The parents interviewed held that the child did not know and did not understand what was done. Some parents are worried if they have separate beds. 
From the description above, there are several factors that influence sexual imitation behavior in children, including (1) the child is still sharing a room with his parents, (2) parents are too possessive in caring for children (3) parents have not been able to provide appropriate sexual education , and (4) learning in schools has not taught sexual education according to the needs of children.

\section{The child is still sleeping together with his parents}

The majority of parents choose to share a room with their children because they feel more comfortable and safe without having to worry about the child's condition. Sleeping in the same room can also allow parents to spend time with children after a day's work. These conditions cause children to become independent. Imitation of behavior occurs because children more easily learn to imitate by observing the actions taken by adults, especially parents repeatedly without thinking about the reason it is done and what impact will arise(Green et al., 1989; Mcguigan et al., 2007).

\section{Parents are very possessive of children.}

The possessive attitude given by the parent adds to the child's curiosity so that the child feels the need to explore his genitals. The differences in genital devices that are owned by peers of different sexes, physical differences between father and mother increasingly add to the child's curiosity so that genital exploration is carried out not only on the genitals. This can be aggravated if parents only give a warning not to explore because it is a dirty, taboo, may not even be a sin. By prohibiting children from repeating it even accompanied by screaming and punishment without adequate explanation will increase the child's curiosity. This is supported by research conducted by Baumeister et al (1995) which states that parent and child communication plays an important role in the sexual development of children, including explaining sex by the development and needs of children.

\section{Parents have not been able to provide appropriate sex education for children.}

Children are often not given proper sexual education from their parents so that children do not find an answer to their curiosity. On the other hand, information about sexuality obtained by children is often not controlled by parents. This is in line with research conducted by Volbert (2000) that children lack information about adequate sex education from parents. Thus children only understand gender differences in men and women and little about differences in body parts even though at the age of 5-7 years children are also expected to already understand the roles and body parts of each gender.

Education in schools does not yet support sexual learning for children, both teachers, and the learning tools used.

The need for sexual education in young children taught in kindergartens where research has not been met. This is evident from the planning of sexual learning that has not been integrated through learning themes. Also, the teacher still believes that the topic is still taboo to be taught at an early age.

\section{Efforts of parents and teachers in dealing with child's sexual imitation behavior}

Parents and teachers play a large role in dealing with sexual imitation behavior committed by children. One method that can be used is through a neurolinguistic approach. For parents, this approach can be done in several ways including (1) Creating a pleasant atmosphere of the room for children. Parents need to pay attention to the condition of the child's room so that children feel comfortable sleeping in his room. This is related to cleanliness and attractive decoration according to the child's preference. (2) Give positive suggestions to children repeatedly, for example through fairy tales before bedtime. Fairy tales conveyed can be an example for children to be bolder like superman figures, Ultraman, and other children's favorite characters. To be able to be independent, children need to be trained by their parents to be able to sleep separately from an early age. An independent definition, in this case, can be interpreted as a child who has been able to meet their needs without expecting others to start from instinctual needs to physical needs. However, the findings from the field of children's independence are still low because parents in caring for their children are still too premise. As a first step in practicing independence, children can sleep separately with their parents since the age of 2 years (Ratih Zulhaqi, 2013). Also, children avoid watching their parents engage in marital relations because it is not appropriate for them to see and listen. The brain can become addicted when the brain is not ready to be exposed to sex.

As a follow-up, the handling that can be done by parents is to teach children to be able to sleep separately and provide positive education and suggestions according to their needs using the neurolinguistic programming approach. This approach makes the communication and visualization patterns used by parents. This is in line with research conducted by Kenny (2009) that by creating comfortable conditions, children will feel safe so they feel confident and brave and comfortable to be invited to communicate. 
While the teacher as one who plays an active role in children's development, the teacher can teach various values of life and character development through play activities including sexual education for children. In the neurolinguistic programming approach, the teacher can use visualization methods and give positive suggestions. However, it should be noted that early childhood education teachers are required to have a different character from teachers at the school level. Likewise, the learning approach applied is very much different from what is done in kindergarten compared to the learning approach at the school level. Teachers are required to be able to provide education and suggestions to children through curriculum development. Learning in kindergarten uses a thematic approach ie there are no subjects in it (Moeslichatoen, 1999). Also, learning is carried out in an integrated manner ie aspects of child development are developed through several activities in one theme and these activities aim to develop one aspect of integrated child development.

Sex education must be appropriate and following the age and needs of children so they can meet the development of curiosity and desire to explore themselves, peers, the differences in genitals and physical conditions. In this case, the teacher can play a role in providing education by integrating it into the themes in the curriculum. The scope of the curriculum that can be used in sex education consists of the areas of moral development and religious, social-emotional, language, cognitive and physical motor values. The subject matter is then formulated into PROSEM (Semester Program), RPPM (weekly learning program plan, and $\mathrm{RPPH}$ (daily learning program plan). Based on the research results obtained that parents inadvertently give examples to their children regarding sexual behavior. Children see their parents in a relationship between husband and wife accidentally when they sleep together. Children's exposure to sexual relations by their parents can cause great curiosity and fantasies that are difficult to control and cause fears that will have an impact on the sexual adaptation of children as adults (Lewis \& Janda, 1988). The curiosity that arises if it is not balanced with adequate explanation can cause children to try to find out for themselves (O'Donnell et al., 2005).

In sex education, children are expected to be able to master two things namely the accuracy of sex roles and how to adjust to the stereotypes of sex roles that are agreed upon in the process and social acceptance (Hurlock, 1999). Early understanding of the role of sex is the responsibility of parents, including how boys are masculine and girls are feminine (Baumeister et al., 1995; Volbert, 2000). This can be done by becoming a source of information, artificial facilitators for boys and girls and as a watchdog for information received by children from the media such as television and the internet (Hetherington, 1965). In providing education about sex, parents can discuss by applying communication skills and testing children's knowledge about sex at home that is supported by natural environmental conditions (Kenny, 2009).

\section{Conclusion}

Based on the description above it can be concluded that children engaging in sexual imitation behavior are influenced by parents' excessive permissive behavior towards their children. This affects the level of independence of the child so that he is unable to sleep separately from his parents. These conditions cause children to accidentally witness their parents having sexual relations so that the impact on children who behave in sexual imitation. To deal with these problems parents and teachers can use the neurolinguistic programming approach. Parents play a role in practice the independence of children by following several ways, namely: (1) creating a pleasant atmosphere for the child (2) giving positive suggestions for example through fairy tales. While the teacher plays a role in providing sex education and positive suggestions in schools by integrating them into the themes in the curriculum through careful planning that is formulating the subject matter into PROSEM, RPPM, and RPPH

\section{References}

Baumeister, L. M., Flores, E., \& Mann, B. V. (1995). Sex information given to Latina adolescents by parents. Health Education Research, 10(2), 233-239.

Boroughs, M. S., Valentine, S. E., Ironson, G. H., Shipherd, J. C., Safren, S. A., Taylor, S. W., ... O'Cleirigh, C. (2015). Complexity of Childhood Sexual Abuse: Predictors of Current Post-Traumatic Stress Disorder, Mood Disorders, Substance Use, and Sexual Risk Behavior Among Adult Men Who Have Sex with Men. Archives of Sexual Behavior, 44(7), 1891-1902. https://doi.org/10.1007/s10508015-0546-9

Dryler, H. (2014). Parental Role Models, Gender and Educational Choice. The British Journal of Sociology, 49(3), 375-398. https://doi.org/10.2307/591389 
Green, B. L., Korol, M., Grace, M. C., Vary, M. G., Leonard, A. C., Gleser, G. C., \& Smitson-Cohen, S. (1989). Children and Disaster: Age, Gender, and Parental Effects on PTSD Symptoms. Journal of the American Academy of Child \& Adolescent Psychiatry, 30(6), 945-951. https://doi.org/10.1097/00004583199111000-00012

Gutermann, J., Schreiber, F., Matulis, S., Schwartzkopff, L., Deppe, J., \& Steil, R. (2016). Psychological Treatments for Symptoms of Posttraumatic Stress Disorder in Children, Adolescents, and Young Adults: A Meta-Analysis. Clinical Child and Family Psychology Review, 19(2), 77-93. https://doi.org/10.1007/s10567-016-0202-5

Hetherington, E. M. (1965). A Developmental Study of The Effects of Sex of The Dominant Parent on Sex Role Preference, Identification, and Imitation in Children. Jounal of Personality and Social Psychology, 2(2), 188-194.

Hornor, G. (2004). Sexual Behavior in Children: Normal or Not? Journal Pediatric Health Care, 18, 57-64. https://doi.org/10.1016/S0891-5245(03)00154-8

Hurlock, elizabeth B. (1996). Psikologi Perkembangan. Suatu Pendekatan Sepanjang Rentang Kehidupan. Ed. 5. Jakarta: Erlangga

Kenny, M. C. (2009). Child Sexual Abuse Prevention: Psychoeducational Groups for Preschoolers and Their Parents. The Journal for Specialists in Group Work, 34(1), 24-42. https://doi.org/10.1080/01933920802600824

Lewis, R. J., \& Janda, L. H. (1988). The Relationship Between Adult Sexual Adjustment and Childhood Experiences Regarding Exposure to Nudity, Sleeping in the Parental Bed, and Parental Attitudes Toward Sexuality. Archives of Sexual Behavior, 17(4), 349-362.

Mcguigan, N., Whiten, A., Flynn, E., \& Horner, V. (2007). Imitation of Causally Opaque Versus Causally Transparent Tool Use By 3- and 5-Year-Old Children. Cognitive Development, 22, 353-364. https://doi.org/10.1016/j.cogdev.2007.01.001

Miller, B. C. (2016). Family Influences on Adolescent Sexual and Contraceptive Behavior Family Influences on Adolescent Sexual and Contraceptive Behavior. The Journal of Sex Research, 39(1), 22-26. https://doi.org/10.1080/00224490209552115

Moeslichatoen. (1999). Metode Pengajaran Di Taman Kanak-Kanak. Jakarta: PT. Rineka Cipta.

O’Donnell, L., Stueve, A., Agronick, G., Wilson-Simmons, R., Duran, R., \& Jeanbaptiste, V. (2005). Saving Sex for Later: An Evaluation Of a Parent Education Intervention. Perspectives on Sexual and Reproductive Health, 37(4), 166-173.

Rustan, E. (2017). Learning Creative Writing Model Based on Neurolinguistic Programming. International Journal of Language Education and Culture Review, 3(2), 13-29. https://doi.org/10.21009/IJLECR.032.02

Squirell, L. (2008). Can Neuro-Linguistic Programming Work With Young Children Who Display Varying Social, Emotional and Behavioural Difficulties. Current Research in NLP, 1, 111.

Tosey, P., \& Mathison, J. (2010). Neuro-linguistic programming as an innovation in education and teaching. Innovations in Education and Teaching International, 47(3), 317-326. https://doi.org/10.1080/14703297.2010.498183

Volbert, R. (2000). Sexual Knowledge of Preschool Children. Journal of Psychology \& Human Sexuality (The Haworth Press, Inc.), 12(1), 5-26. https://doi.org/10.1300/J056v12n01_02

Wurtele, S. K. (1993). Enhancing Children's Sexual Development Through Child Sexual Abuse Prevention Programs. Journal of Sex Education and Therapy, 19(1), 37-46. https://doi.org/10.1080/01614576.1993.11074068 